\title{
BMJ Global Health Abortion-related morbidity in six Latin American and Caribbean countries: findings of the WHO/HRP multi- country survey on abortion (MCS-A)
}

To cite: Romero M, Gomez Ponce de Leon R, Baccaro LF, et al. Abortionrelated morbidity in six Latin American and Caribbean countries: findings of the WHO/HRP multi-country survey on abortion (MCS-A). BMJ Global Health 2021;6:e005618. doi:10.1136/ bmjgh-2021-005618

Handling editor Seye Abimbola

- Supplemental material is published online only. To view, please visit the journal online (http://dx.doi.org/10.1136/ bmjgh-2021-005618).

Received 5 March 2021 Accepted 10 June 2021

Check for updates

(c) Author(s) (or their employer(s)) 2021. Re-use permitted under CC BY. Published by BMJ.

For numbered affiliations see end of article.

Correspondence to Dr Mariana Romero; mromero@cedes.org

\section{ABSTRACT}

Introduction Abortion-related complications are a significant cause of morbidity and mortality among women in many Latin American and Caribbean (LAC) countries. The objective of this study was to characterise abortionrelated complication severity, describe the management of these complications and report women's experiences with abortion care in selected countries of the Americas region. Methods This is a cross-sectional study of 70 health facilities across six countries in the region. We collected data on women's characteristics including sociodemographics, obstetric history, clinical information, management procedures and using Audio ComputerAssisted Self-Interviewing (ACASI) survey the experience of abortion care. Descriptive bivariate analysis was performed for women's characteristics, management of complications and reported experiences of abortion care by severity of complications, organised in five hierarchical mutually exclusive categories based on indicators present at assessment. Generalised linear estimation models were used to assess the association between women's characteristics and severity of complications.

Results We collected data on 7983 women with abortionrelated complications. Complications were classified as mild (46.3\%), moderate (49.5\%), potentially lifethreatening (3.1\%), near-miss cases $(1.1 \%)$ and deaths $(0.2 \%)$. Being single, having a gestational age of $\geq 13$ weeks and having expelled products of conception before arrival at the facility were significantly associated with experiencing severe maternal outcomes compared with mild complications.

Management of abortion-related complications included both uterotonics and uterine evacuation for two-thirds of the women while one-third received uterine evacuation only. Surgical uterine evacuation was performed in $93.2 \%$ (7437/7983) of women, being vacuum aspiration the most common one (5007/7437, 67.4\%).

Of the 327 women who completed the ACASI survey, $16.5 \%$ reported having an induced abortion, $12.5 \%$ of

\section{Key questions}

What is already known?

- Globally, Latin America and Caribbean (LAC) region has the most legally restrictive abortion laws and policies.

- Complications as a result of abortions account for $9.9 \%(8.1-13)$ of maternal deaths in the LAC region.

- Estimates of post-abortion complications indicate that the LAC has lower rates than Asia and Africa with a regional rate of 5.3 per 1000 women aged 15-44 years (around 757000 women per year) reflecting a decrease from previous estimates (7.7 in 2005).

What are the new findings?

- This is one of the few global studies to provide data on abortion-related complications, collecting data across 70 health facilities in six LAC countries using a standardised tool.

- This study provides insights on the burden and management of abortion-related complications in health facilities in LAC region, using a hierarchal severity gradient, according to sociodemographic, obstetric and clinical characteristics.

- Although most women in our study were classified as having mild or moderate complications, the proportion of women with potentially life-threatening complications and with severe maternal outcomes (including death) is still high.

the women stated that they were not given explanations regarding their care nor were able to ask questions during their examination and treatment with percentages increasing with the severity of morbidity.

Conclusions This is one of the first studies using a standardised methodology to measure severity of abortionrelated complications and women's experiences with 


\section{Key questions}

What do the new findings imply?

- The prevalence of these severe complications varies across countries illustrating that abortion continues to be a major public health and policy challenge to address in the LAC region.

- Future research in the region should focus on measurement of abortion-related complications using the standardised methodology proposed in this study to document the severity of abortion-related complications in the region.

abortion care in LAC. Results aim to inform policies and programmes addressing sexual and reproductive rights and health in the region.

\section{INTRODUCTION}

Estimates suggest that between the years 2015 and 2019, around 73 million abortions occurred worldwide annually. ${ }^{1}$ Based on figures from 2014, almost a half of abortions were unsafe, with $97 \%$ taking place in developing countries. ${ }^{2}$ However, what constitutes abortion safety has been an evolving discussion, particularly after the evidence-based WHO recommendations related to methods, providers and settings, based on gestational age, was published..$^{3-5}$ In the advent of misoprostol and mifepristone, availability of information and access to these medications for women, WHO has been developing and updating its guidelines on abortion and postabortion care. ${ }^{5-7}$ Abortion safety has been recognised as a multidimensional concept that taps into the continuum of existing risks and takes into account social determinants such as the legal context, access and equity. As a result, a theoretical framework was developed where abortion safety is classified in three groups: safe, less safe and least safe. ${ }^{8}$ By applying these categories, Latin America has the highest proportion of 'less safe' abortion among all regions. ${ }^{2}$

This data become relevant in the light of an evolving scenario where women and providers have started to switch from unsafe methods to misoprostol, reducing the severity of complications due to its effectiveness and safety. Estimates of post-abortion complications indicate that the Latin American region has lower rates than Asia and Africa, with a regional rate of 5.3 per 1000 women aged 15-44 years (around 757000 women per year) reflecting a decrease from previous estimates (7.7 in 2005). ${ }^{4}$ Rates of post-abortion complications per 1000 women aged 15-44 years range from 2.4 in Brazil to 10.3 in Dominican Republic. ${ }^{4}$ However, official data may not be reliable enough to inform programmatic and policy decisions. ${ }^{9}$ Estimations stem from national statistics on hospital discharges, with the majority being from the public health sector, which can lead to under-reporting due to the sensitivity of the issue and the difficulties in capturing the true nature of the reported abortions (spontaneous or induced) in the region. ${ }^{31011}$
To better understand the context, it is important to highlight that the Latin America and Caribbean (LAC) region has the most legally restrictive abortion laws and policies globally, limiting the provision of safe abortion and post-abortion quality care. Across the region, abortion is legal on request in three countries only (Cuba, Uruguay and Guyana), while abortion is prohibited in all circumstances in four countries (El Salvador, Honduras, Nicaragua and the Dominican Republic). ${ }^{12}$ It has been shown that there is an association between proportion of unsafe abortion and highly restrictive laws, suggesting that an enabling environment and legal grounds play a role in abortion safety. ${ }^{8}$ The WHO safe abortion: technical and policy guidance for health systems recommends that regulatory, policy and programmatic barriers that hinder access to and timely provision of safe abortion care should be removed. ${ }^{4}$ Lately attempted changes in penal codes like in the case of Bolivia trying to legalise abortion up to 8 weeks or abortion legalisation in Argentina up to 14 weeks, that created a 'green wave' across the continent, are promoting change at the national and regional levels. ${ }^{13}$

At the same time, women's receipt of person-centred and respectful abortion care has also become an area of growing of research interest in the region. ${ }^{14}$ However, as pointed out by Darney et al, very little evidence exists documenting client perceptions of both technical or interpersonal quality, especially from low- and middleincome country settings. ${ }^{15}$

In an effort to capture accurate information surrounding abortion-related complications and postabortion care, $\mathrm{WHO} / \mathrm{HRP}$ conducted the multi-country survey on abortion (MCS-A)-related morbidity to evaluate the burden and severity of abortion-related complications and management among women presenting to health facilities in countries from Africa and LAC. We also explored abortion safety characteristics according to WHO definition and the experience of care reported by women. ${ }^{7}$ This paper reports the results of this survey in six countries from the LAC region.

\section{METHODS}

\section{Study design and participants}

The protocol of the WHO/HRP MCS-A study is published elsewhere. ${ }^{16}$ Briefly, it is a large cross-sectional study with prospective data collection across 280 health facilities from 17 countries in Africa and LAC regions. In this article, we focus on the findings from 70 health facilities across six LAC countries: Argentina, Bolivia, Brazil, Dominican Republic, El Salvador and Peru. Facilities were identified through a multistage sampling method once countries were selected. A second stage of sampling consisted of random selection of two provinces/states, with probability proportional to the population size, plus the capital city/metropolitan area. Once the geographical areas were selected, 10 facilities per state/province 
(up a total of 30 facilities per country) from the census of private and public facilities were selected.

Health facilities were eligible if they fulfilled the following characteristics: $>1000$ deliveries per year, gynaecology ward, surgical capability to provide emergency obstetrical care including removal of retained products and, abortion provision and/or post-abortion care based on the facility assessment forms (online supplemental annex I). To ensure sufficient data contribution, facilities reporting less than 10 post-abortion care patients per month were excluded.

A hospital administrator or a healthcare provider responsible for the gynaecology and obstetrics wards at each participating facility provided institutional-level data. All women presenting to the facility with signs and symptoms from abortion-related complications or early pregnancy loss (including ectopic and molar pregnancies) or death at discharge were included for medical record review. Women with a diagnosis of threatened abortion, defined as vaginal bleeding with a closed cervix were excluded. The criterion of reviewing medical records of all women presenting to the facilities, rather than admissions, was used to avoid exclusion of those seeking care for mild complications. Included women were eligible for the exit survey if admitted for a minimum of 24 hours and experienced at least one of the following conditions: infection, haemorrhage/anaemia, perforated organs or injury to reproductive organs, complications resulting in operative management, and were able and willing to consent.

We obtained written informed consent (WIC) from all women participating in the exit surveys. No WIC was requested to collect data from medical records except for Bolivia and Brazil where National Institutional Review Board indicated that WIC must be obtained from every woman accounted in the study. Institutional informed consent was obtained from the responsible authority of each facility. Research Ethical Review Committee at WHO and at health authorities of each country, as well as those of all hospitals, independently approved the protocol.

\section{Data collection and data management}

Trained research assistants abstracted socio-demographic and clinical information from medical records including age, marital status, education, obstetrics characteristics, signs and symptoms of abortion-related complications, medical procedures, clinical outcomes and vital status at discharge. We transcribed data into paper-based case report forms and entered it into a web-based electronic data capture system developed by the Centro Rosarino de Estudios Perinatales. Data for the exit survey were collected using Audio Computer-Assisted Self-Interviewing (ACASI), a system developed by Tufts University. ${ }^{17}$ ACASI data consisted of abortion safety characteristics (method used, provider, setting), and experience of abortion care related to effective communication, respect and dignity and emotional support. As in previous WHO multi-country surveys, data managers in Argentina monitored the study data flow and validated data quality. In each country, data collection took place over a 3-month period between June 2018 and January 2019.

\section{Statistical analysis}

Based on clinical indicators at hospital admission, laboratory markers and management-based indicators during hospitalisation up to discharge or death, women were grouped into five hierarchical categories: mild complications, moderate complications, potentially-life threatening complications, near-miss and deaths (figure 1). Based on WHO identification criteria for maternal near-miss and potentially life-threatening complications (PLTC), we combined mortality and near-miss complications as severe maternal outcomes (SMO) ${ }^{18}$ Identification criteria are shown in online supplemental annex II. Furthermore, using the WHO Global Abortion Policies Database, we described the legal environments surrounding abortion provision, medication availability and abortion protocols across the six countries (online supplemental annex III). ${ }^{12}$

We performed descriptive analysis on national and facility level characteristics, as well as socio-demographic, obstetric and clinical management factors, by comparing proportions of characteristics across abortion-related complication severity categories using $\chi^{2}$ test. Country specific severity burden of abortion-related complications was computed as number of complications per 1000 women for each severity category and their $95 \%$ CIs estimated.

To determine women's characteristics potentially associated with abortion-related complications, separate generalised linear regression models were fitted to estimate the odds of moderate, potentially life-threatening and severe complications compared with mild category for socio-demographic and obstetric characteristics (age, marital status, prior pregnancies, gestational age and expulsion of the products of conception (POC) before arrival at the facility), adjusting for potential clustering effect by country.

Gestational age at presentation was grouped as $<13$ weeks, $\geq 13$ weeks or undetermined weeks. We categorised the clinical management of abortion-related complications as managed by uterotonics only, by uterine evacuation only, or by both methods. We further divided uterotonic use into single agents and their combination; and uterine evacuation by type of procedure: vacuum aspiration, dilation and curettage (D\&C), or both.

For self-reported data collected by ACASI, we performed descriptive analysis to evaluate the abortion methods used, information received and help sought to end pregnancy. Experience of abortion care during facility stay was assessed by comparing responses across severity of abortion-related complications using $\chi^{2}$ test. Data analysis was conducted using SAS (V.9.4). 


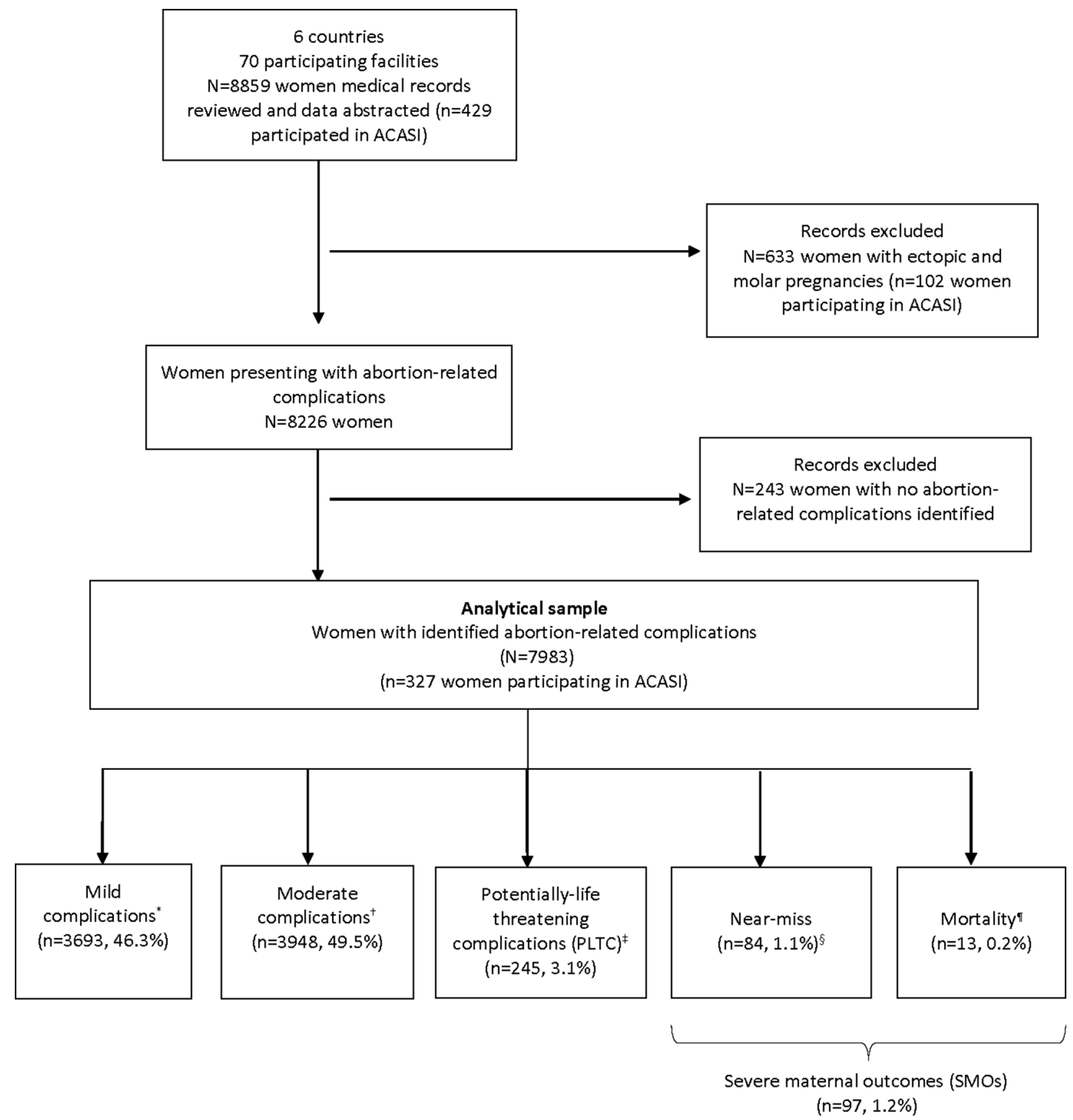

Figure 1 Study flow diagram for severity of abortion-related complications across six Latin American and Caribbean countries. ACASI, Audio Computer-Assisted Self-Interviewing. *Mild complications based on abnormal physical examination findings on initial assessment (vital signs, appearance, mental status, abdominal examination, gynaecological examination); †Moderate complications (heavy bleeding, suspected intra-abdominal injury, or infection); $¥ W H O$ potentially-life threatening conditions (severe haemorrhage, severe systemic infection or suspected uterine perforation); §WHO maternal near-miss criteria (organ dysfunction of either one or more of the following: cardiovascular, respiratory, renal, coagulation, hepatic, neurologic or uterine dysfimction); ๆStatus at discharge.

\section{RESULTS}

We collected data from 70 facilities in six LAC countries. Forty-one $(57.8 \%)$ were tertiary level facilities. Further details of the health facilities characteristics can be found in online supplemental annex I.

A total of 8859 women seeking care with signs and symptoms of abortion-related complications or early pregnancy loss (including ectopic and molar pregnancies) were included, from which 8226 (92.9\%) had complications of abortions and $633(7.1 \%)$ had complications of molar or ectopic pregnancies. This analysis focused on abortion-related complications, therefore we excluded molar and ectopic pregnancies. We further excluded 243 cases because severity could not be determined. The final analysis included data on 7983 women with abortionrelated complications (figure 1 ).

Based on the inclusion criteria, 484women with abortion-related complications were eligible for ACASI, from which $327(67.5 \%)$ consented to participate in the exit interview. Of note, all eligible women from El Salvador declined to participate. Eligibility criteria and participation per country can be found in online supplemental annex IV.

\section{Severity of abortion-related complications}

From 7983women who had abortion-related complications, $46.3 \%$ had mild complications, $49.5 \%$ had moderate complications, $3.1 \%$ had PLTC, $1.1 \%$ of 
Mid

\section{Potentially-life threatening complications}

\section{Severe Maternal Outcomes}

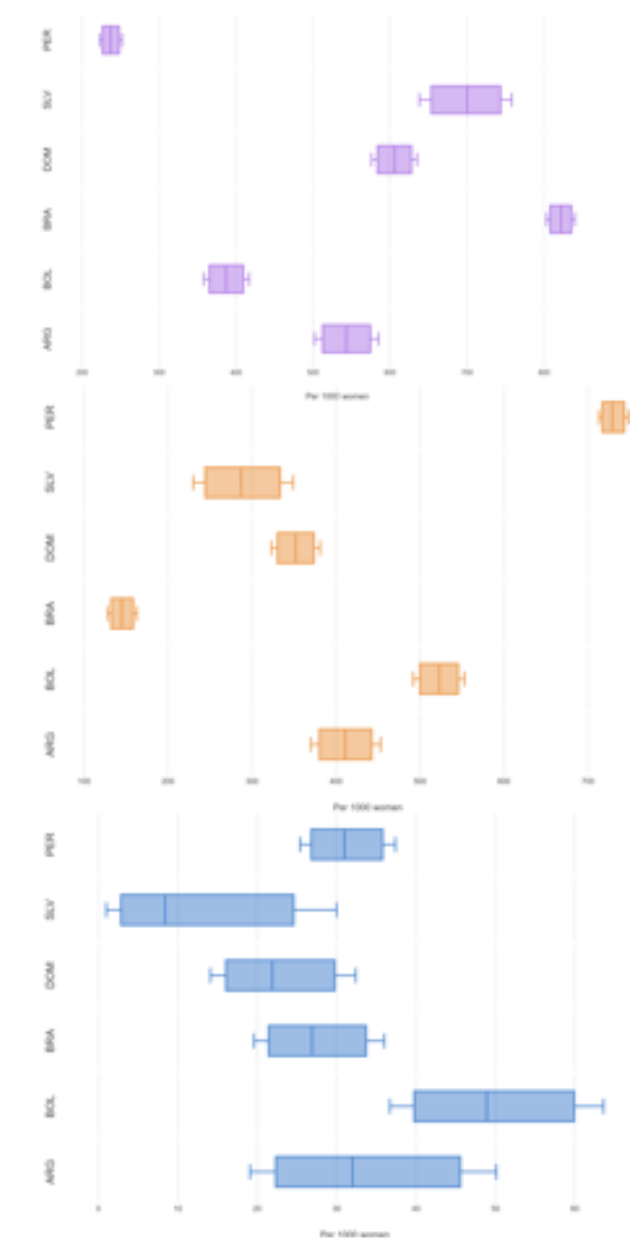

Figure 2 Severity of abortion-related complications by country. ${ }^{1}$ Figures are drawn to scale for each severity category. ARG, argentina; BOL, bolivia; BRA, brazil; DOM, dominican republic; SLV, El Salvador; PER, peru.

women were identified as near-miss cases and there were 13 deaths $(0.2 \%)$ (figure 1$)$. Deaths and near-miss were grouped as SMO, totalling 97 cases (1.2\%). Across countries, severity burden for SMO and PLTC were higher for Bolivia while moderate and mild complications were higher for Peru and Brazil, respectively (figure 2).

Most women seeking care for abortion complications were seen in facilities from countries where abortion is permitted only under certain indications. Some of these countries have National Guidelines for both Induced Abortion and Post-Abortion Care in use (table 1). Misoprostol is approved and registered for gynaecological indications except in El Salvador where it is not registered but included in the National List of Essential Medicines. Mifepristone is not registered in any of the study countries. Approximately $96 \%$ of women were treated at secondary or tertiary level facilities, predominantly in an urban setting.

Women presenting to facilities with abortion-related complications were predominantly between 20 and 29 years old, married or cohabitating and reporting secondary education or above. Only one-third of them were employed gainfully. Distribution of these sociodemographic factors were observed to be significantly different across the severity groups (table 2 ). 
Table 1 Legal status of abortion among six participating Latin American and Caribbean countries

\begin{tabular}{ll}
\hline Legal classification & Country \\
\hline Law prohibits all abortion & $\begin{array}{l}\text { Dominican Republic, } \\
\text { El Salvador }\end{array}$ \\
$\begin{array}{l}\text { Unlawful abortion is prohibited or } \\
\text { where there are only penalties for } \\
\text { unlawful abortion, with no additional } \\
\text { information provided about lawful } \\
\text { abortion }\end{array}$ & None \\
$\begin{array}{l}\text { Law allows or permits abortion only } \\
\text { on one or more legal grounds }\end{array}$ & $\begin{array}{l}\text { Argentina, Bolivia, } \\
\text { Law entitles a woman to abortion }\end{array}$ \\
$\begin{array}{l}\text { on request with no requirement for } \\
\text { justification }\end{array}$ & \\
\hline
\end{tabular}

Moreover, three out of four women had a previous pregnancy and approximately two in five women $(41.1 \%)$ reported having had a prior abortion. Additionally, three-quarters of women presenting with abortionrelated complications were determined to be at $<13$ weeks gestational age and significantly greater proportion of women in the SMO or potentially life-threatening groups had expelled products of conception prior to arrival at the facility compared with those in the mild or moderate groups $(58.7 \%$ and $62.6 \%$ vs $41.6 \%$ and $35.7 \%$, respectively).

Table 3 presents generalised linear models evaluating factors potentially associated with increased risk of severe abortion-related complications. ${ }^{19}{ }^{20}$ Being single (adjusted OR=1.9; 95\% CI 1.1 to 3.3), presenting with gestational age $\geq 13$ weeks (adjusted OR=1.8; 95\% CI 1.2 to 2.7) and having expulsion of products of conception before arrival at the facility (adjusted OR=1.8; 95\% IC 1.3 to 2.4) were significantly associated with experiencing SMOs compared with mild complications, after adjusting for country clustering effect, and potential confounding by age, marital status, prior pregnancy, gestational age and expulsion of products of conception. Comparing women with PLTC to those with mild complications, expulsion of POC before arrival to the facility was found to be the single factor associated with increased severity of PLTC (adjusted $\mathrm{OR}=3.2$; 95\% CI 2.4 to 4.7), after adjusting for country clustering effect, age, marital status, prior pregnancy and gestational age. There were no differences between moderate and mild complications.

\section{Management of abortion-related complications}

Table 4 details the management of abortion-related complications by severity group. Overall, almost two-third of women received both uterotonics and uterine evacuation, one-third received uterine evacuation only and very few $(3.9 \%)$ received uterotonics only. In the group of women with SMO the use of uterotonics only was higher, and the use of uterine evacuation only was lower than in the rest of morbidity categories.
Most women seeking care for abortion complications received uterine evacuation $(7437 / 7983,93.2 \%)$ with D\&C performed on approximately one-third (2360/7437, 31\%). Among women with PLTC, the combination of vacuum aspiration and D\&C was substantially higher $(5.2 \%)$ than in mild, moderate and severe health outcomes groups $(0.36 \%, 0.45 \%$ and $1.2 \%$, respectively).

Only $3.3 \%$ of women received blood transfusion, and less than $1 \%$ needed a surgical intervention. Massive transfusions ( $>3$ units) and surgeries were more frequent among severe cases, as well as the admission to intensive care unit (ICU) (table 5).

Figure 3 describes the use of uterotonics and uterine evacuation for the management of abortion-related complications by gestational age $(<13$ and $\geq 13$ weeks). Women were managed similarly across both gestational age groups, irrespective of their severity. There was a higher use of uterine evacuation only in earlier pregnancies $(<13$ weeks), and lower use of uterotonics alone in gestations $\geq 13$ weeks, except in the cases of SMO.

\section{Women's self-reported experiences of care via ACASI}

Overall, 327 women participated in the ACASI exit interviews, and the distribution of sociodemographic and obstetrical characteristics of these women were not significantly different from the overall study population except for gainful occupation, gestational age and expulsion of POC before arrival (online supplemental annex V). A greater proportion of women who responded ACASI had $\geq 13$ weeks of pregnancy $(29.1 \%$ vs $12.5 \%$ ) and had expelled products of conception before arrival $(50.9 \%$ vs 39.7) which may reflect the need for a longer stay at the hospital as indicated in the eligibility criteria for ACASI.

Of 327 women, $54(16.5 \%)$ reported an induced abortion. Among those, $46.3 \%$ stated that they did not receive information from anyone about methods used to end pregnancy. The most commonly reported sources of information were friends (29.6\%), medical doctor (22.2\%), someone else (18.5\%) or husband/partner/boyfriend (16.7\%). (table 6). In terms of seeking care from someone to end their pregnancy, $37 \%$ of the women reported not getting any help. The most reported assistance was from medical doctors $(37 \%)$, a friend $(24.1 \%)$ or someone else $(16.7 \%)$ (online supplemental annex VI).

Table 6 presents experience of abortion care during facility stay as reported by women. Three out of four women encountered anxiety and stress during the hospital stay in similar proportions across severity. Overall, $12.5 \%$ of the women stated that they were not given explanations regarding their care and treatment and $12.8 \%$ women reported that they were not able to ask questions during their examination and treatment with percentages increasing with the severity of morbidity.

\section{DISCUSSION}

This paper reports the results of a study aimed at surveying abortion-related complications and its management in women seeking care to health facilities in six LAC 
Table 2 National, sociodemographic and obstetrical characteristics of study population by severity of abortion-related complications

\begin{tabular}{|c|c|c|c|c|}
\hline $\begin{array}{l}\text { Total } \\
\text { (N=7983) }\end{array}$ & $\begin{array}{l}\text { Mild } \\
(\mathrm{N}=3693)\end{array}$ & $\begin{array}{l}\text { Moderate } \\
(\mathrm{N}=3948)\end{array}$ & $\begin{array}{l}\text { Potentially } \\
\text { life-threatening } \\
\text { complications } \\
\text { (N=245) }\end{array}$ & $\begin{array}{l}\text { Severe } \\
\text { maternal } \\
\text { outcomes } \\
(\mathrm{N}=97)\end{array}$ \\
\hline
\end{tabular}

\section{National}

Misoprostol country recognised approval $\dagger^{\star *}$

\begin{tabular}{|lrrrrr}
\hline No & $237(2.9)$ & $166(4.5)$ & $68(1.7)$ & $2(0.8)$ & $1(1)$ \\
\hline Yes & $7746(97)$ & $3527(95.5)$ & $3880(98.3)$ & $243(99.2)$ & $96(98.9)$ \\
\hline National guidelines on abortionsł $\ddagger^{* *}$ & & & & & \\
\hline Post-abortion care (PAC) Only & $1332(16.7)$ & $829(22.5)$ & $453(11.5)$ & $26(10.6)$ & $24(24.7)$ \\
\hline Both (induced abortion and PAC) & $6651(83.3)$ & $2864(77.6)$ & $3495(88.5)$ & $219(89.4)$ & $73(75.3)$ \\
\hline
\end{tabular}

\section{Facility}

Facility type ${ }^{\star \star}$

\begin{tabular}{lccccc}
\hline Primary & $288(4.3)$ & $269(7.4)$ & $19(0.7)$ & 0 & 0 \\
\hline Secondary & $2238(33.7)$ & $1086(29.9)$ & $1024(37.9)$ & $99(43.4)$ & $29(30.9)$ \\
\hline Tertiary & $4120(61.9)$ & $2267(62.6)$ & $1659(61.4)$ & $129(56.6)$ & $65(69.2)$ \\
\hline Other referral level & $1337(16.8)$ & $71(1.9)$ & $1246(31.6)$ & $17(6.9)$ & $3(3.1)$ \\
Location** $^{\star *}$ & & & & & \\
$\quad$ Urban & $7252(90.9)$ & $3224(87.3)$ & $3698(93.7)$ & $235(95.9)$ & $95(97.9)$ \\
\hline Peri-urban & $675(8.5)$ & $438(11.9)$ & $225(5.7)$ & $10(4.1)$ & $2(2.1)$ \\
\hline Rural & $56(0.7)$ & $31(0.8)$ & $25(0.6)$ & 0 & 0
\end{tabular}

\section{Sociodemographic and obstetrical}

\begin{tabular}{|c|c|c|c|c|c|}
\hline Age (in years) ${ }^{*}$ & 7963 & & & & \\
\hline$\leq 19$ & $964(12.1)$ & $500(13.6)$ & $429(10.9)$ & $24(9.8)$ & $11(11.5)$ \\
\hline $20-29$ & $3720(46.7)$ & $1705(46.3)$ & $1850(46.9)$ & $118(48.4)$ & $47(48.9)$ \\
\hline$\geq 30$ & 3279 (41.2) & $1476(40.1)$ & $1663(42.2)$ & $102(41.8)$ & 38 (39.6) \\
\hline Marital status* & 7356 & & & & \\
\hline Single & 2355 (32) & $1146(48.7)$ & 1099 (46.7) & 78 (34.9) & $32(34.8)$ \\
\hline Married/cohabitating & $4871(66.1)$ & $2211(64.2)$ & $2452(68.2)$ & $140(62.8)$ & $58(63)$ \\
\hline Separated/divorced/widowed & $140(1.9)$ & $86(2.5)$ & $47(1.3)$ & $5(2.2)$ & $2(2.2)$ \\
\hline Education* & 6736 & & & & \\
\hline No education & $72(1.1)$ & $42(1.3)$ & $26(0.8)$ & $1(0.5)$ & $3(3.8)$ \\
\hline Primary & $865(12.8)$ & $514(16.3)$ & $308(9.4)$ & 25 (12.4) & 18 (22.8) \\
\hline Secondary or more & $5799(86.1)$ & 2605 (82.4) & 2960 (89.9) & $176(87.1)$ & $58(73.4)$ \\
\hline Gainful occupation* & 6441 & & & & \\
\hline Yes & 2017 (31.3) & $987(31.8)$ & $926(30.2)$ & 73 (39.3) & $31(38.3)$ \\
\hline No & $4424(68.7)$ & $2116(68.2)$ & $2145(69.9)$ & $113(60.8)$ & $50(61.7)$ \\
\hline Previous pregnancies* & 7944 & & & & \\
\hline 1 or more & 5960 (75) & 2771 (75.6) & 2912 (74) & $199(81.2)$ & 78 (80.4) \\
\hline 0 & $1984(24.9)$ & $896(24.4)$ & $1023(26)$ & $46(18.8)$ & 19 (19.6) \\
\hline $\begin{array}{l}\text { Previous abortions (in women reporting } \\
\text { previous pregnancies) }\end{array}$ & 5958 & & & & \\
\hline 1 or more & $2451(41.1)$ & $1169(42.2)$ & $1169(40.1)$ & $76(38.4)$ & $37(47.4)$ \\
\hline 0 & 3507 (58.9) & $1601(57.8)$ & 1743 (59.9) & $122(61.6)$ & 41 (52.3) \\
\hline \multicolumn{6}{|l|}{ Gestational age (in weeks) ${ }^{\star \star}$} \\
\hline$<13$ & 5886 (73.7) & 2808 (76) & 2856 (72.3) & $159(64.9)$ & $63(64.9)$ \\
\hline
\end{tabular}




\begin{tabular}{|c|c|c|c|c|c|}
\hline & $\begin{array}{l}\text { Total } \\
(\mathrm{N}=7983)\end{array}$ & $\begin{array}{l}\text { Mild } \\
(\mathrm{N}=3693)\end{array}$ & $\begin{array}{l}\text { Moderate } \\
(\mathrm{N}=3948)\end{array}$ & $\begin{array}{l}\text { life-threatening } \\
\text { complications } \\
(\mathrm{N}=245)\end{array}$ & $\begin{array}{l}\text { maternal } \\
\text { outcomes } \\
(\mathrm{N}=97)\end{array}$ \\
\hline$\geq 13$ & 995 (12.5) & 515 (13.9) & 405 (10.3) & 56 (22.9) & 19 (19.6) \\
\hline Undetermined & 1102 (13.8) & $370(10)$ & $687(17.4)$ & 30 (12.2) & $15(15.5)$ \\
\hline $\begin{array}{l}\text { Expulsion of products of conception } \\
\text { before arrival to facility }{ }^{\star \star}\end{array}$ & 7716 & & & & \\
\hline No & 4655 (60.3) & 2313 (64.3) & $2218(58.4)$ & $86(37.4)$ & 38 (41.3) \\
\hline
\end{tabular}

${ }^{*} \mathrm{P}$ value $<0.05 ;{ }^{* *} \mathrm{p}$ value $<0.0001$

†None: El Salvador (although misoprostol is listed in the National List of Essential Medicines) / misoprostol: Argentina, Bolivia, Brazil, Dominican Republic, Peru / mifepristone: not registered in any of the countries.

¥PAC only: Dominican Republic, El Salvador / Both: Argentina, Bolivia, Brazil, Peru.

countries. It also includes an assessment of the quality of care women received from their own perspective. The resulting regional sample included countries (Argentina, Bolivia, Brazil, Dominican Republic, El Salvador, Peru) with diverse scenarios in terms of the legal restrictions, availability of abortion medications and guidelines. Although most women in our study were classified as having mild or moderate complications, the proportion of women with PLTCs and with SMOs (including deaths) are still high. The prevalence of moderate, PLTC and SMO account for $53.8 \%$ illustrating that complications as a result of abortions continue to be a major public health and policy challenge to address in the LAC region.

The main findings from this study also revealed that severe abortion-related complications were associated with being single, later gestational age $(\geq 13$ weeks) and

Table 3 Determinants* of increased risk of abortion-related complication severity compared with mild complications

\begin{tabular}{|c|c|c|c|c|c|c|c|}
\hline & \multicolumn{2}{|c|}{ Moderate† versus mildł } & \multicolumn{2}{|c|}{ PLTC§ versus mildł } & \multicolumn{2}{|c|}{ SMOๆ versus mildł } \\
\hline & & AOR & $95 \% \mathrm{Cl}$ & AOR & $95 \% \mathrm{Cl}$ & AOR & $95 \% \mathrm{Cl}$ \\
\hline \multirow[t]{3}{*}{ Age (in years) } & $\leq 19$ years & 0.8 & 0.7 to 1 & 0.9 & 0.7 to 1.1 & 0.9 & 0.5 to 1.8 \\
\hline & 20-29 years & 0.9 & 0.9 to 1 & 1 & 0.7 to 1.6 & 0.9 & 0.6 to 1.3 \\
\hline & $\geq 30$ years & Reference & Reference & Reference & Reference & Reference & Reference \\
\hline \multirow[t]{2}{*}{ Marital status } & Single & 1.2 & 0.9 to 1.8 & 1.5 & 0.9 to 2.7 & $1.9^{\star \star}$ & 1.1 to 3.3 \\
\hline & Other than single & Reference & Reference & Reference & Reference & Reference & Reference \\
\hline \multirow[t]{2}{*}{ Prior pregnancies } & 1 or more & 0.9 & 0.8 . to 0.9 & 1.3 & 0.9 to 1.9 & 1.3 & 0.8 to 1.9 \\
\hline & 0 & Reference & Reference & Reference & Reference & Reference & Reference \\
\hline \multirow{3}{*}{$\begin{array}{l}\text { Gestational age } \\
\text { (in weeks) }\end{array}$} & $\geq 13$ & 0.7 & 0.4 to 1.5 & 2.2 & 0.8 to 6.3 & $1.8^{\star \star}$ & 1.2 to 2.7 \\
\hline & Undetermined & 0.7 & 0.5 to 1.1 & 0.9 & 0.3 to 2.7 & 0.79 & 0.6 to 1.5 \\
\hline & $<13$ & Reference & Reference & Reference & Reference & Reference & Reference \\
\hline \multirow{2}{*}{$\begin{array}{l}\text { Expulsion of } \\
\text { products of } \\
\text { conception } \\
\text { before arrival to } \\
\text { facility }\end{array}$} & Yes & 1.2 & 0.7 to 2.2 & $3.2^{\star \star}$ & 2.2 to 4.7 & $1.8^{\star \star}$ & 1.3 to 2.4 \\
\hline & No & Reference & Reference & Reference & Reference & Reference & Reference \\
\hline
\end{tabular}

*Models clustered around country.

†Moderate complications (heavy bleeding, suspected intra-abdominal injury or infection).

$\ddagger$ Mild complications (based on abnormal physical examination findings on initial assessment (vital signs, appearance, mental status,

abdominal examination, gynaecological examination)).

§PLTC, potentially-life threatening complications (WHO potentially-life threatening conditions (severe haemorrhage, severe systemic infection or suspected uterine perforation)).

ISMOs, severe maternal outcomes (WHO near-miss criteria and mortality).

${ }^{*} \mathrm{P}$ value $<0.05$

AOR, adjusted OR. 
Table 4 Uterotonics and uterine evacuation for management of abortion-related complications by severity

Severity of abortion-related complications

\begin{tabular}{|c|c|c|c|c|c|c|}
\hline \multirow[b]{2}{*}{$\begin{array}{l}\text { Management of } \\
\text { complications }\end{array}$} & \multirow[b]{2}{*}{$\begin{array}{l}\text { Total } \\
(\mathrm{N}=7983)\end{array}$} & \multicolumn{5}{|c|}{ severity от abortion-related complications } \\
\hline & & $\begin{array}{l}\text { Mild } \\
(\mathrm{N}=3693)\end{array}$ & $\begin{array}{l}\text { Moderate } \\
(\mathrm{N}=3948)\end{array}$ & $\begin{array}{l}\text { Potentially } \\
\text { life-threatening } \\
\text { complications } \\
(\mathrm{N}=245)\end{array}$ & $\begin{array}{l}\text { Severe maternal } \\
\text { outcomes }(\mathrm{N}=97)\end{array}$ & P value \\
\hline Uterotonics & 315 (3.9) & $183(4.9)$ & $116(2.9)$ & $8(3.3)$ & $8(8.3)$ & $<0.0001$ \\
\hline Uterine evacuation & 2565 (32.1) & 1161 (31.4) & 1299 (32.9) & $82(33.5)$ & $23(23.7)$ & \\
\hline $\begin{array}{l}\text { Both uterotonics and } \\
\text { uterine evacuation }\end{array}$ & $4872(61)$ & $2206(59.7)$ & $2460(62.4)$ & $148(60.4)$ & 58 (59.8) & \\
\hline Other & $90(1.1)$ & $47(1.3)$ & $31(0.8)$ & $5(2)$ & 7 (7.2) & \\
\hline None & $141(1.8)$ & $96(2.6)$ & $42(1.1)$ & $2(0.8)$ & $1(1)$ & \\
\hline
\end{tabular}

${ }^{*} \mathrm{P}$ value $<0.0001$ based on $\chi^{2}$ for each management category by severity.

†Mutually exclusive.

expulsion of POC prior to arrival to the facility. Although these findings show an association between each individual factor and morbidity outcomes, further analysis is required to understand the potential conditions and sequence of events leading to different results in the spectrum of severity. Several studies in the region concur with findings that support the association of being single or having a lower educational status with delays in accessing abortion care. ${ }^{21} 22$ Others show that even when misoprostol is available contributing to decrease abortion-related complications, barriers on accessing information on use, dosage and expected outcomes make women misinterpret warning signs affecting when to seek care. ${ }^{23-25}$

Even though the participating numbers were small, women's responses in the ACASI exit survey showed that $46 \%$ did not have any previous information on how to end a pregnancy. ${ }^{27}$ Among those who stated having some information, friends and physicians were the most frequently reported source. Moreover, physicians or medical doctors were the most cited as having helped to end the pregnancy. This shows willingness of health professionals to provide help and information in restrictive contexts, which constitutes a rather new scenario probably due to regional initiatives that appealed to professionalism and ethics in relation to the duty of providing information as a way of reducing unsafe abortion practices. ${ }^{28}$

Our study is part of the larger WHO/HRP MCS-A that includes 11 countries in Africa using the same methodology allowing comparability. ${ }^{30}$ SMOs and PLTC reported for Africa $(7 \%)$ are almost double those of our region (4.3\%). Additionally, the majority of women in LAC were seeking post-abortion care at an earlier gestational age (under 13 weeks) than in Africa (73.7\% vs $52.8 \%$ ). These results support the findings related to abortion safety where in LAC most women seek care for unsafe abortions that could be categorised as less safe, whereas in Africa, almost all unsafe abortions were classified as least safe. ${ }^{2}$ Factors that might explain these differences in LAC could be the transition from the use of dangerous methods to misoprostol outside the formal health system, as well as a better access to care and treatment of abortion-related complications when they occur. ${ }^{2431}$ Studies on the women's perspectives show greater access to information and methods, and accompaniment, while on the providers' side, less stigma and a high level of awareness of potential complications are seen ${ }^{32}{ }^{33}$ Although this transition has improved overall indicators, it is not homogeneous, nor stable in the region, and facilities are far from implementing WHO recommendations consistently in practice. ${ }^{46}$ Similar to the Africa region, D\&C is still used in the management of abortion-related complications in LAC. Overall, 3 in 10women received it despite longstanding efforts from WHO, PAHO/CLAP, FIGO and other agencies, to promote the use of safer uterine evacuation methods such as manual vacuum aspiration. ${ }^{34}$ The combined use of uterotonics and uterine evacuation for 6 out of 10 women seems to be high, and suggest probable over-medicalisation or overtreatment in all severity and gestational age groups. However, we have not explored individual medical indications nor justifications for combined or sequential medical/ surgical treatments to confirm this. Nevertheless, the most frequently used uterotonic in LAC was misoprostol (42.6\%), in contrast with the use of oxytocin by half of the cases reported in the Africa study.

Through the exit surveys, there is a similarity among women participating in both LAC and Africa MCS-A studies, regarding their perceptions as to how well they were informed about care and treatment by providers $(87.5 \%$ and $79.9 \%)$ and feeling doctors provided everything needed to know about decisions taken for care $(84.5 \%$ and $79.3 \%) .{ }^{30}$ Results are similar to those obtained in studies in Brazil, Argentina and Mexico that show an improvement in the proportion of women receiving information compared with previous studies. ${ }^{35-37}$ However, information sources differed between the two regions where information stemmed from friends and physicians in LAC whereas the internet and social media were highlighted as key sources in the Africa study. More than 7 out of 10 women participating in the study experienced post-abortion care with a degree of anxiety and stress. Fear of being mistreated, stigmatised or being reported, still persist in the region as revealed by several studies analysed by López Gómez, 
Table 5 Types of management by severity of abortion-related complications $\dagger$

\section{Severity of abortion-related complications}

\begin{tabular}{|c|c|c|c|c|c|}
\hline & \multirow[b]{2}{*}{$\begin{array}{l}\text { Total } \\
\text { (N=7983) }\end{array}$} & & & & \\
\hline & & $\begin{array}{l}\text { Mild } \\
(\mathrm{N}=3693)\end{array}$ & $\begin{array}{l}\text { Moderate } \\
(\mathrm{N}=3948)\end{array}$ & $\begin{array}{l}\text { Potentially life-threatening } \\
\text { complications } \\
\text { ( } \mathrm{N}=245)\end{array}$ & $\begin{array}{l}\text { Severe maternal } \\
\text { outcomes }(\mathrm{N}=97)\end{array}$ \\
\hline Uterotonics ${ }^{*}$ & $5187(64.9)$ & $2389(64.7)$ & $2576(65.3)$ & $156(63.7)$ & $66(68)$ \\
\hline Misoprostol & $2207(42.6)$ & 709 (29.7) & $1470(57.1)$ & $20(12.8)$ & $8(12.1)$ \\
\hline Oxytocin & $801(15.4)$ & $366(15.3)$ & $364(14.1)$ & $56(35.9)$ & $15(22.7)$ \\
\hline $\begin{array}{l}\text { Oxytocin and } \\
\text { ergometrine }\end{array}$ & $782(15.1)$ & $328(13.7)$ & $402(15.6)$ & $34(21.8)$ & $18(27.3)$ \\
\hline Ergometrine & $712(13.7)$ & $536(22.4)$ & $145(5.6)$ & $20(12.8)$ & $11(16.7)$ \\
\hline $\begin{array}{l}\text { Misoprostol and } \\
\text { oxytocin }\end{array}$ & $340(6.6)$ & $217(9.1)$ & $99(3.8)$ & $99(3.8)$ & $217(9.1)$ \\
\hline $\begin{array}{l}\text { Misoprostol and } \\
\text { ergometrine }\end{array}$ & $194(3.7)$ & $156(6.5)$ & $35(1.4)$ & $1(0.6)$ & $2(3)$ \\
\hline $\begin{array}{l}\text { Misoprostol, oxytocin } \\
\text { and ergometrine }\end{array}$ & $135(2.6)$ & $69(2.9)$ & $56(2.2)$ & $6(3.9)$ & $4(6.1)$ \\
\hline Other & $16(0.31)$ & $8(0.33)$ & $5(0.19)$ & $2(1.3)$ & $1(1.3)$ \\
\hline Uterine evacuation* & $7437(93.2)$ & 3367 (91.2) & $3759(95.2)$ & $230(93.9)$ & $81(83.5)$ \\
\hline Vacuum aspiration & $5009(67.4)$ & 2010 (59.7) & 2818 (74.9) & $127(55.2)$ & $54(66.7)$ \\
\hline $\begin{array}{l}\text { Dilation and curettage } \\
\text { (D\&C) }\end{array}$ & $2360(31.7)$ & $1330(39.5)$ & $913(24.3)$ & $91(39.6)$ & $26(32.1)$ \\
\hline $\begin{array}{l}\text { Both vacuum aspiration } \\
\text { and D\&C }\end{array}$ & $42(0.56)$ & $12(0.36)$ & $17(0.45)$ & $12(5.2)$ & $1(1.2)$ \\
\hline Other & $26(0.35)$ & $15(0.45)$ & $11(0.29)$ & 0 & 0 \\
\hline Blood transfusion* & $261(3.3)$ & $32(0.87)$ & $104(2.6)$ & $99(40.4)$ & $26(26.8)$ \\
\hline 1 unit & 83 (31.8) & $10(31.3)$ & $41(39.4)$ & $28(28.3)$ & $4(15.4)$ \\
\hline 2 units & $125(47.9)$ & $16(50)$ & $52(50)$ & $47(47.5)$ & $10(28.5)$ \\
\hline 3 units or more & $53(20.3)$ & $6(18.8)$ & $11(10.6)$ & $24(24.2)$ & $12(46.2)$ \\
\hline Surgical procedures* & $38(0.48)$ & $13(0.35)$ & $12(0.30)$ & $5(2)$ & $8(8.3)$ \\
\hline Laparoscopy & $4(10.5)$ & $1(7.7)$ & $2(16.7)$ & 0 & $1(12.5)$ \\
\hline Exploratory laparotomy & $10(26.3)$ & $5(38.5)$ & $2(16.7)$ & $2(40)$ & $1(12.5)$ \\
\hline Hysterectomy & 24 (63.2) & 7 (53.9) & $8(66.7)$ & $3(60)$ & $6(75)$ \\
\hline $\begin{array}{l}\text { Antibiotics received for } \\
\text { prophylaxis or treatment* }\end{array}$ & $5299(66.4)$ & $2114(57.2)$ & 2906 (73.6) & 207 (84.5) & $72(74.2)$ \\
\hline $\begin{array}{l}\text { Admission to intensive } \\
\text { care unit* }\end{array}$ & $33(0.4)$ & $8(0.22)$ & $5(0.13)$ & $6(2.5)$ & $14(14.4)$ \\
\hline
\end{tabular}

${ }^{*} P$ value $<0.0001$

†Not mutually exclusive.

showing that the transition to a women centred care is still to be realised. ${ }^{32}$

To our knowledge, this is one of the few studies evaluating abortion morbidity and its management in the LAC region. Given the legal and political context, the available studies in the region address mostly maternal morbidity due to pregnancy and delivery using a cut point of 22 weeks gestational age and higher as eligibility criteria. ${ }^{38}$ The limited evidence from the region hinders the comparability of our findings. Standardised measurement of these complications in the LAC region is key to understand the extent of the burden that unsafe abortion poses on maternal morbidity and mortality reduction. In 2015, the Latin American Center for Perinatology and Women's Reproductive Health (CLAP), a specialised centre from the PAHO, created a regional network of institutions in 16 countries, committed to improving healthcare and epidemiological surveillance for women receiving abortion care or facing a near-miss event using the Perinatal Information System (SIP). This network plays a very important role in applying the WHO recommendations in different legal settings and has reported results of post-abortion contraception and spontaneous abortion care. ${ }^{40-42}$

The restrictive legal and policy environment may serve as the determinant of abortion safety. ${ }^{2}$ Research has 


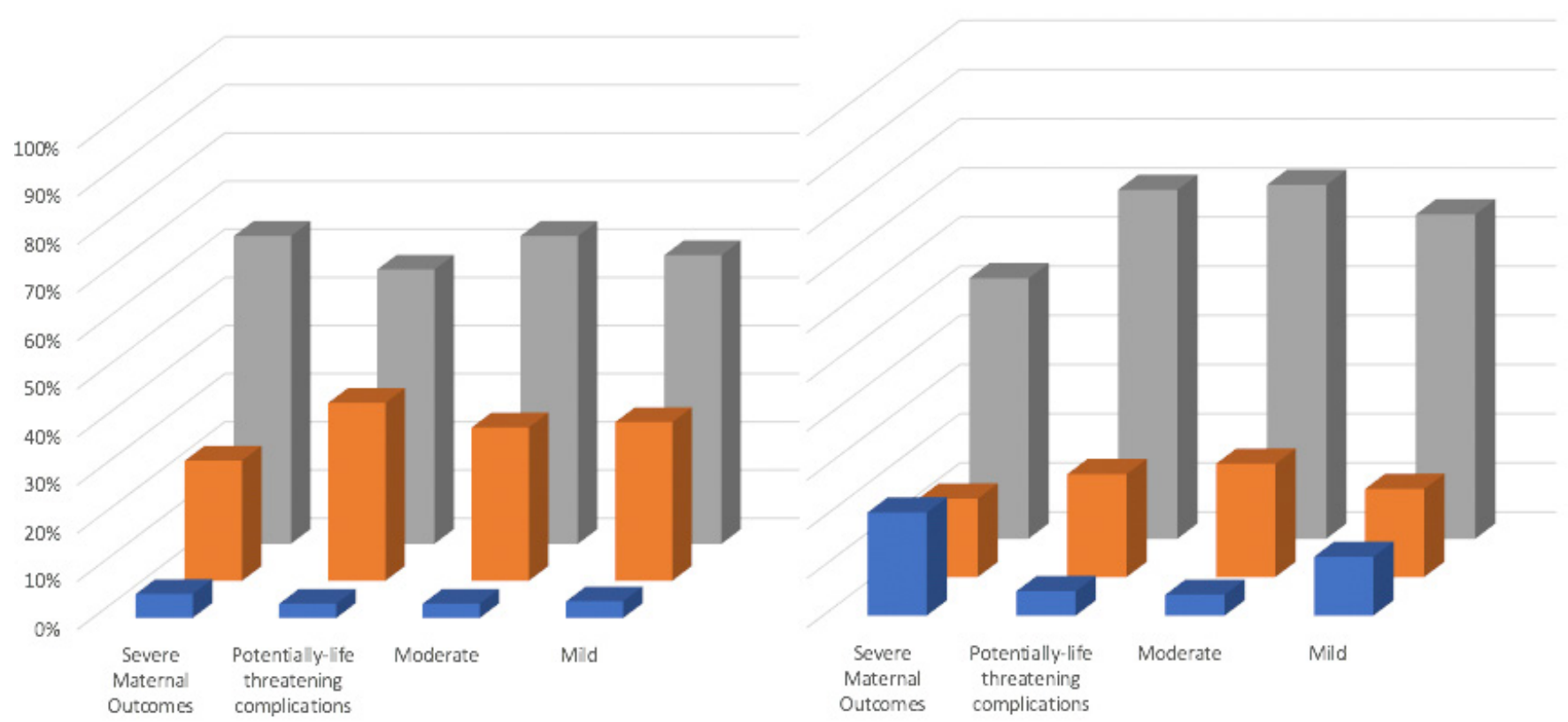

- Uterotonics = Uterine Evacuation utero tonics and uterine evacuation

Figure 3 Use of uterotonics and uterine evacuation for management of abortion-related complications, by severity and gestational age.

shown that globally, women have limited awareness and knowledge of the abortion laws and policy environment, even in countries with liberal laws, impeding women from accessing available services. ${ }^{43}$ In restrictive settings, such as the LAC region, abortion laws are sometimes worded in vague terms as to what is actually allowed in practice. ${ }^{44}$ The lack of transparency on abortion laws and policies and, the stigma surrounding abortion may lead women to seek delayed care or to avoid the health system entirely due to the lack of information on how and when to seek post-abortion care. The WHO safe abortion: technical and policy guidance for health systems recommends that regulatory, policy and programmatic barriers that hinder access to and timely provision of safe abortion care for all women should be removed. ${ }^{44}{ }^{45}$ While access to safe and comprehensive abortion care, including post-abortion care is key, access to legal information is also critical. Future research using the information available on the WHO Global Abortion Policies Database may help to increase transparency and, to improve knowledge of providers and women's understanding of abortion laws and policies to seek safe post-abortion care. ${ }^{44}$

\section{Strengths and limitations}

This study reached a sample size of almost 8000 women presenting at public hospitals with abortion-related morbidity from six countries of LAC. It is the first study in the region to address this public health problem with a standardised classification based on WHO criteria. It not only collected data from clinical records but also interviewed women to assess their perceptions on quality of care. Another strength of the study is the inclusion of countries with varying degrees of restrictive abortion laws, in particular two countries (El Salvador and Dominican Republic) where abortion is penalised under all circumstances.

A limitation is that the contribution of each country to the sample may not reflect the true proportionality of the population, the country heterogeneity and the heterogeneity of institutions. For example, the most populated province of Argentina, Buenos Aires, refused to participate and it is worth noting that none of the women in El Salvador accepted to participate in ACASI. Pooling data across countries has enabled us to have sufficient data to look at some of the associations, but at the same time it may limit some of the analyses masking between-country differences.

Even though the severity of abortion-related complications among women who presented to the facilities varied across study countries, this being a cross-sectional profile may not be representative of the entire population, not only because many women may choose to remain at home, but also because the sample excluded private institutions, rural areas, and adolescents.

\section{CONCLUSIONS}

This is one of the first studies of its kind and scope using a standardised methodology to measure severity of abortion-related complications and women's experiences 
Table 6 Self-reported experience of abortion care during facility stay

Severity of abortion-related complications

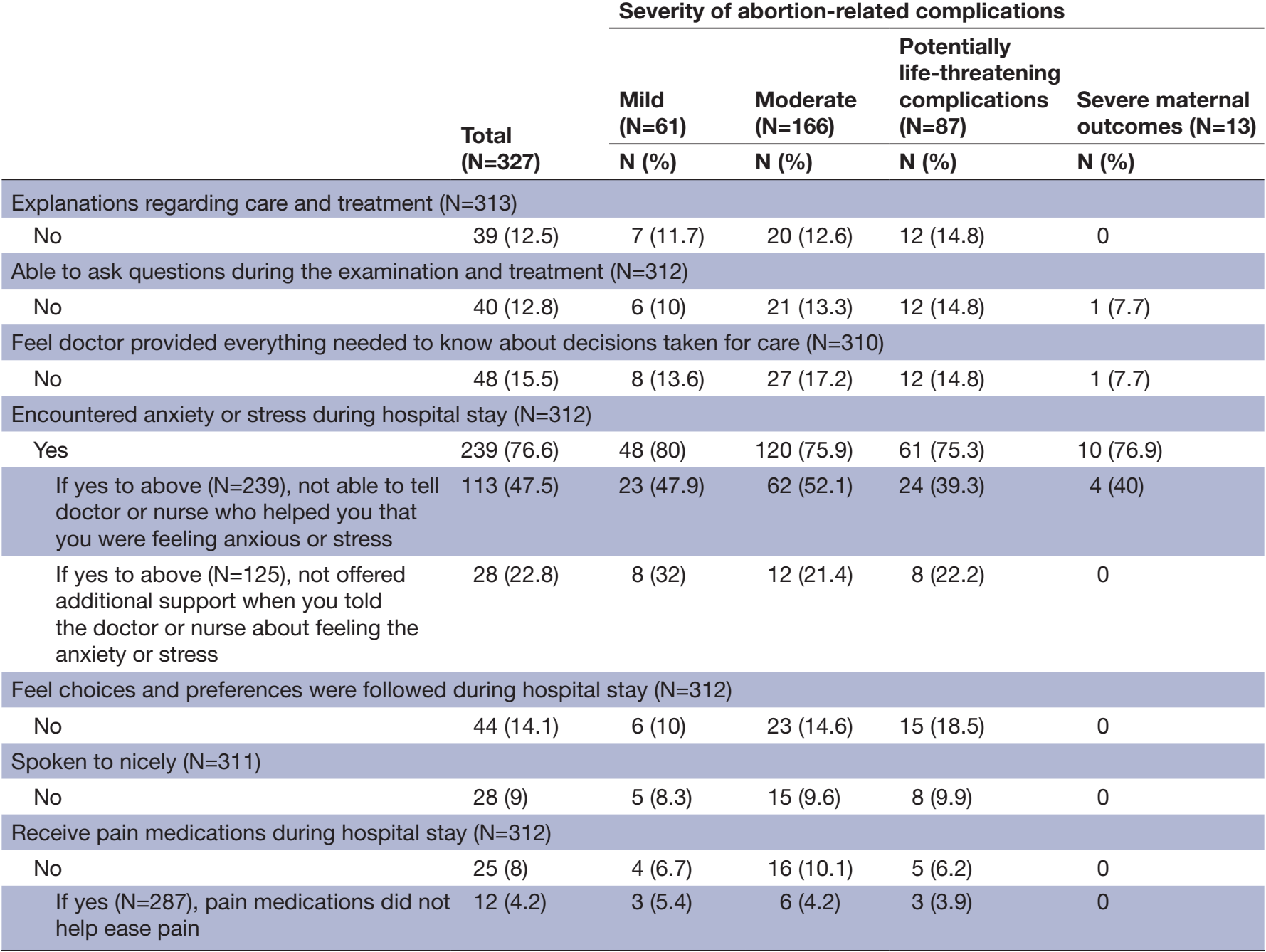

in their own voices in LAC and, will provide evidence to improve public policies addressing sexual and reproductive rights and health in the region. While showing a transition towards improved overall morbidity, results emphasise other areas of concern: persistence of curettage, limited use of misoprostol and limited awareness of women's needs along the process of care. Future research in the region should focus on measurement of abortion-related complications using the standardised methodology developed in this study to document the severity of abortion-related complications. By measuring these complications and better understanding women's reported experiences, we will be able to determine the extent of the burden of maternal morbidity and mortality and monitor the results of implementing public policies fostering universal health coverage and Sustainable Development Goals in the region.

\section{Author affiliations}

${ }^{1}$ Health, Economy and Society Department, CEDES, Buenos Aires, Argentina ${ }^{2}$ CONICET, Buenos Aires, Argentina

${ }^{3}$ Latin American Center for Perinatology/Women's Health and Reproductive Health, Pan American Health Organization (CLAP/WR-PAHO/WHO), Montevideo, Uruguay
${ }^{4}$ UNICAMP, Campinas, Brazil

${ }^{5} \mathrm{CREP}$, Rosario, Santa Fe, Argentina

${ }^{6}$ UNDP/UNFPA/UNICEF/WHO/World Bank Special Programme of Research, Development and Research Training in Human Reproduction (HRP), Department of Sexual and Reproductive Health and Research, WHO, Geneva, Switzerland ${ }^{7}$ Pan American Health Organization El Salvador, San Salvador, El Salvador ${ }^{8}$ Hospital Materno Infantil San Lorenzo de los Mina, Santo Domingo, Dominican Republic

${ }^{9}$ ESSALUD, Lima, Peru

${ }^{10}$ Pan American Health Organization Bolivia, La Paz, Bolivia, Plurinational State of

Twitter Mariana Romero @mromero64, Luiz Francisco Baccaro @luizbaccaro, Hedieh Mehrtash @hediehmm and Özge Tuncalp @otuncalp

Acknowledgements The WHO multi-country survey on abortion (MCS-A) is a research project implemented by the WHO across a network of health facilities in Latin America. We sincerely thank the women who participated in this study. WHO is grateful to the extensive network of institutions and individuals who contributed to the project design and implementation, including researchers, study coordinators, data collectors, data clerks and other partners including the staff from the Ministries of Health and WHO offices. All listed authors are members of the WHO MCS-A Research Group. The WHO MCS-A Research Group is grateful to the following professionals for their contributions to the study: In Argentina: Adolfo Martiré, Ingrid DiMarco, Florencia Salesi, Alejandro Hakim, Analía Messina, Rubén Vicente Luca, Lucía Di Biase, Natalia Righetti, Silvina Paladino, Emiliano Pucherman, Andrea Marzán, María Laura González, Katherine Ballivian, María Sofía Torcoletti, Giuliana Cantero, Gonzalo Prieto, Rodrigo Scaravonati, Carolina Ramírez Picollo, Micaela Martín, Damián Serrano López, Hospital Álvarez, María 
Beatriz Lahítte Eberbach, Yanina Miragaya, María Elena Calo, Damián Levy, Morina Caffoni, Lucía Gómez, Silvina Andrea Mazzeo, Daniela Inés Gil, María Carolina Vignera, Silvina Manau, Hernán Maciá, Carolina Ramborger, Milagros Cuenca, Samanta Antoniazzi, Samuel Seiref, Judith Suarez Espinosa, Camila Wagner, Eliana Colombo, Laura Demircy, Julieta Carrasco, Fernando Ponzo, Mariela Itati Ramírez, Flavia Carolina Gomez, Patricia Elena Romero, Oscar Marcelo Mena, Enrique Manuel Mesa, Paula Luciani, Cristian Ormaechea, Federico Rukavina, Luisina Sanchi, Paula Ceolatto, Maria Leticia Acosta, Daiana Voghera, Daniela Dri, Valeria Zanuttini, Daniela Latuada, Nerina Mattio, María Nerina Azpeitia, Solange Daniela Pentorari, Sandra Formia, Oraldo Llanos, Alberto Simioni, Daniel Teppaz, Débora Sabbag, Eugenia Vinocur. In Bolivia: Eunice Miranda Navia, Victoria Calisaya Mamani, Igor Pardo Zapata, Elvio Jesús Fernandez, Estrada, Victor Conde Altamirano, José Napoleón Ramírez Tapia, Rosmery Aida Mamani Quispe, Freddy Jerez Retamozo, Hugo Renzo Collareta Andrade, José Luis Barriga Vera, Rubén Dario Costa Benavides, Paula Angela Silva Ramos, Vanessa Kimberly Valencia Herbas, Germán Carlos Parisaca Apaza, Javier Caihuara Llanos, Neiza Gómez, Carla Ozuna Chavarría, Roberto Baldiviezo Calles, Rosana Flores Victoria, Fernando Diego Abastoflor Cáceres, Glenda Ghelen Montaño Castro, Verónica Vargas Vargas, Maida Rejas Flores, Wilmar Benito Giron Mampazo, Kelly Delina Zárate Flores, Aurora Jurado Lipe, Elizabeth Fabiana Tambo Morales, Mayra Gabriela Zapata Poma, Geraldine Lesly Surco Mamani, Mariela Medina Torrez, Marin Linwer Huacani Nina, Lady Condori Matías, Rosbel Roberto Marti Capote, Patricia Llanos Torrico, Patricio David Flores Yañez, Pilar Concepción Moscoso Mena, Leny Ivonne Tudela Aruquipa, Mariel Susana Sánchez Jurado, Gustavo Martínez Saldías, Cristina Apaza Leandro, Celia Palli Mercado, Gabriela Rosario Lima Gómez, Leidy Mamani Troche, Hugo Reynaldo Almaraz Monzón, Olivia Nina Parisaca. In Brazil: Adriana Barros, Adriana Mendonça S. Alexandrino, Alexandre Volta Andrade do Nascimento, Camila Tereza Camilo Clerot, Cintya Andreia Do Nascimento Santos. Claudia Lucrécia De Matos Silva, Claudio Lucio De Medeiros Albuquerque, Débora Paulo Santos, Demétrio Antonio Gonçalves Da S. Gomes, Édson Cunha De Araújo Junior, Elizabete Vilanova, Georgina Costa Teixeira, Graciete Helena Nascimento Dos Santos, Guilherme Augusto Guerra Avelar, lara Elce Lopes Barros, Jaqueline Polon Abboud, Jeane Cristina Antas Lins, Joanne Thalita Pereira Silva, Juliana Dytz Fagundes Ribeiro, Kelma H. Aguiar De Lucena, Lara Wanderley Paes Barbosa, Leandro Lima, Lia Siquiera, Lidiane Silva De Almeida, Luciana De Melo Freitas Carneiro, Lucila Nagata, Márcia Alice Satte Da Silva, Márcia De Oliveira Pereira Lúcio, Márcia Helena De Campos Miguel, Maria Cleane Rodrigues Da Silva, Maria Da Conceição Ribeiro Simões, Maria De Fátima Silva De Souza, Maria Fernanda Da Mota Magalhães, Mariana Viana Almeida, Michelle Regina Faria Lira, Nádia Martins De Paula Souza, Rafael Martins Papa, Rafael Ribeiro Matos, Renata Porto Pinheiro, Roberta Souza Dos Anjos, Silvana Muller, Suelen Miranda De Jesus, Tedy Roger Flores Ynturias, Valéria Cristina Gonçalves, Vilma Zotareli, Viviane Resende De Abreu Caetano. In Dominican Republic: Jocelyn Sánchez Santana, Bianchi Duarte, Albert Carvajal, Raquel Rosso, Héctor Herrera, Dayissell Ricour Pujol, Pedro Mejía, Michel Trinidad, Reyna Arias, Elvis Fernández, Milvia Solís, Adalgisa Jiménez, Yorka Arias. In El Salvador: Marta Sonia Hernandez, José Manuel Beza, Dra. Maria Isabel Rodriguez, Melissa Alejandra Molina, Cecilia Ceron, Roberto Aquino de la 0. In Peru: Maria Del Pilar Huatuco Hernandez, Santiago Guillermo Cabrera Ramos, Celia Isabel Morales Galvez, Pedro Segundo Aguirre Mata Mauro Reyes Acuña, Joyce Corina Arango Garayar, Antonio Luna Figueroa, Angela Del Rosario Padilla Montoro, Gerson Gustavo Ramos Vega, Pablo Ricardo Moreno Martinez, Silvia Constanza Huamani Cueto, Victor Hugo Aburto Loroña, Milagros Orostegui Arenas, Raul Cesar Alegria Guerrero, Ruth Sucso Ramirez, Juan Carlos Wong, Alfredo Nuñez Villar, Magnon Tulio Ramirez Saldaña, Monica Leonor Quesada Porras, Jorge Antonio Huatuco Hernandez, Ivonne Rosmery Villalobos Robles, Pedro Gabriel Aldave Paredes, Mariangella Susan Lau Raza, Gustavo Cornejo Falcon, Deysi Luzmila Becerra Malca, Victor Raul Villavicencio Abad, Mercedes Emperatriz Diaz Jimenez, Johanny Del Milagro Navarro Adanaque.

Contributors CRK, ÖT, RGPdL, SST, BG, MG and GC participated in developing the study protocol. MR, LFB, BC, JR, EM, EES-H, MdPH and RHM participating in adapting the protocol and instruments to each site as well as coordinated data collection and revision. GGC, LC, DG and HG were responsible for data management of the study. HM and SST performed the statistical analysis. MR, HM, EA, ÖT, SST, CRK and GC developed the first draft of the paper. All authors made substantial contributions to the conception or design of the work; or the acquisition, analysis or interpretation of data for the work; drafted the work and/or revised it critically for important intellectual content; gave the final approval of the version to be published; and agreed to be accountable for all aspects of the work in ensuring that questions related to the accuracy or integrity of any part of the work are appropriately investigated and resolved.
Funding UNDP/UNFPA/UNICEF/WHO/World Bank Special Programme of Research, Development and Research Training in Human Reproduction (HRP), Department of Sexual and Reproductive Health and Research, WHO, Geneva, Switzerland.

\section{Competing interests None declared.}

\section{Patient consent for publication Not required.}

Ethics approval This multi-country study protocol was approved by the WHO Human Reproduction Programme (HRP) Review Panel on Research Projects, the WHO Ethical Review Committee (protocol: 0002699) and the Independent Ethical Committee of the Centro Rosarino de Estudios Perinatales. This study was also approved by country ethical committees in: Argentina (Comité de Ética en Investigación, Gobierno de la Ciudad de Buenos Aires; Comités de Docencia e Investigación y Comités de Ética de Hospital de General de Agudos Dr. T. Álvarez, Hospital General de Agudos Ramos Mejía, Hospital General de Agudos Cosme Argerich, Hospital General de Agudos Donación Santojanni, Hospital Materno Infantil Dr. Ramón Sardá, Comité de Investigación y Docencia Hospital Escuela Eva Perón; Comité de Ética en Investigación, Gobierno de la Ciudad de Santa Fe; Comité de Investigación y Docencia de la Secretaría de Salud de Rosario; Comité de Docencia del Hospital Dra. Olga Stucky, Comité de Docencia del Hospital Provincial del Centenario, Comité de Ética de la Investigación del Hospital Provincial de Rosario, Comité de Docencia e Investigación del Hospital Roque Saénz Peña, Comité de Ética en Investigación del Hospital J. M. Cullen, Comité de Docencia e Investigación del Hospital J. B. Iturraspe). Bolivia (Comité Nacional de Bioética; Comité de Revisión Ética (PAHO-ERC)); Brazil (Comissao Nacional de Ética em Pesquisa (CONEP), Fundação de Ensino e Pesquisa em Ciências da Saúde/ FEPECS/ SES/ DF, Secratario de Estado de Saude de Distrito Federal ; UNICAMP ; Centro Universitario Do Maranhao); Dominican Republic (Servicio Nacional de Salud; Hospital Ricardo Limardo; Hospital de la Mujer Dominicana, Hospital Docente Maternidad de Nuestra Señora de Altagracia, Hospital Marcelino Vélez, General Vinicio Calventi, Hospital Materno Infantil San Lorenzo de Ios Mina, Hospital Reynaldo Almaza); El Salvador (Comité de Ética en Investigación Clínica, Ministerio de Salud); Peru (Comité Institucional de Ética en Investigación, Ministerio de Salud, Peru; Instituto Nacional Materno Perinatal, Ministerio de Salud; ESSALUD; Gobierno Regional Piura; Hospital Nacional Docente Madre Niño San Bartolomé, Hospital Nacional Sergio E. Bernales, Hospital San Juan de Lurigancho, Hospital María Auxiliadora, Comité de Evaluación Metodológico y Estadística en la Investigación y Comité de Ética en Investigación Hospital Nacional Materno Perinatal, Comité de Capacitación, Investigación y Docencia Hospital Nacional Eduardo Rebagliati Martins, Comité de Capacitación, Investigación y Docencia Hospital Nacional Guillermo Almera Irigoyen, Comité de Ética para la Investigación Hospital Uldarico Rocca Fernandez, Comité de Investigación Hospital de la Amistad Perú Corea Santa Rosa II, Comité de Investigación Hospital III José Cayetano Heredia).

Provenance and peer review Not commissioned; externally peer reviewed.

Data availability statement Data are available upon request. The data used for this analysis might be made available upon reasonable request, in accordance with the WHO/HRP MCS-A Research Group data sharing policy and WHO Policy of Data Use and Data Sharing. For further information, contact srhmph@who.int and srhpua@who.int.

Supplemental material This content has been supplied by the author(s). It has not been vetted by BMJ Publishing Group Limited (BMJ) and may not have been peer-reviewed. Any opinions or recommendations discussed are solely those of the author(s) and are not endorsed by BMJ. BMJ disclaims all liability and responsibility arising from any reliance placed on the content. Where the content includes any translated material, BMJ does not warrant the accuracy and reliability of the translations (including but not limited to local regulations, clinical guidelines, terminology, drug names and drug dosages), and is not responsible for any error and/or omissions arising from translation and adaptation or otherwise.

Open access This is an open access article distributed in accordance with the Creative Commons Attribution 4.0 Unported (CC BY 4.0) license, which permits others to copy, redistribute, remix, transform and build upon this work for any purpose, provided the original work is properly cited, a link to the licence is given, and indication of whether changes were made. See: https://creativecommons.org/ licenses/by/4.0/.

\section{REFERENCES}

1 Bearak J, Popinchalk A, Ganatra B, et al. Unintended pregnancy and abortion by income, region, and the legal status of abortion: estimates from a comprehensive model for 1990-2019. Lancet Glob Health 2020;8:e1152-61. 
2 Ganatra B, Gerdts C, Rossier C, et al. Global, regional, and subregional classification of abortions by safety, 2010-14: estimates from a Bayesian hierarchical model. Lancet 2017;390:2372-81.

3 World Health Organization. Maternal health and safe motherhood programme. the prevention and management of unsafe abortion: report of a technical Working Group (WHO/MSM/92.5). Geneva: World Health Organization, 1993.

4 Singh S, Maddow-Zimet I. Facility-based treatment for medical complications resulting from unsafe pregnancy termination in the developing world, 2012: a review of evidence from 26 countries. BJOG 2016;123:1489-98.

5 World Health Organization. Safe abortion: technical and policy guidance for health systems. 2nd. Geneva: World Health Organization, 2012.

6 World Health Organization. Clinical practice Handbook for safe abortion. Geneva: World Health Organization, 2014.

7 World Health Organization. Medical management of abortion. Geneva: World Health Organization, 2018.

8 Ganatra B, Tunçalp Özge, Johnston HB, et al. From concept to measurement: operationalizing who's definition of unsafe abortion. Bull World Health Organ 2014;92:155.

9 Johnson BR, Lavelanet AF, Schlitt S. Global abortion policies database: a new approach to strengthening knowledge on laws, policies, and human rights standards. BMC Int Health Hum Rights 2018;18:35.

10 Singh S. Hospital admissions resulting from unsafe abortion: estimates from 13 developing countries. Lancet 2006;368:1887-92.

11 Rossier C. Estimating induced abortion rates: a review. Stud Fam Plann 2003;34:87-102.

12 World Health Organization. Global abortion policies database. Available: http://srhr.org/abortion-policies [Accessed Oct 2020].

13 Galli B. Challenges and opportunities for access to legal and safe abortion in Latin America based on the scenarios in Brazil, Argentina, and Uruguay. Cad Saude Publica 2020;36Suppl 1:e00168419.

14 Madeira S, Pileggi V, Souza JP. Abuse and disrespect in childbirth process and abortion situation in Latin America and the Caribbeansystematic review protocol. Syst Rev 2017;6:152.

15 Darney BG, Powell B, Andersen K, et al. Quality of care and abortion: beyond safety. BMJ Sex Reprod Health 2018;44:159-60.

16 Kim CR, Tunçalp Özge, Ganatra B, et al. Who Multi-Country survey on Abortion-related morbidity and mortality in health facilities: study protocol. BMJ Glob Health 2016;1:e000113.

17 Kane JC, Murray LK, Sughrue S, et al. Process and implementation of audio computer assisted Self-Interviewing (ACASI) assessments in low resource settings: a case example from Zambia. Glob Ment Health 2016;3:e24.

18 Say L, Souza JP, Pattinson RC, et al. Maternal near miss--towards a standard tool for monitoring quality of maternal health care. Best Pract Res Clin Obstet Gynaecol 2009;23:287-96.

19 Sihvo S, Bajos N, Ducot B, et al. Women's life cycle and abortion decision in unintended pregnancies. J Epidemiol Community Health 2003;57:601-5.

20 Barrett G, Peacock J, Victor CR. Are women who have abortions different from those who do not? a secondary analysis of the 1990 national survey of sexual attitudes and lifestyles. Public Health 1998;112:157-63.

21 Baum S, DePiñeres T, Grossman D. Delays and barriers to care in Colombia among women obtaining legal first- and second-trimester abortion. Int J Gynaecol Obstet 2015;131:285-8.

22 Saavedra-Avendano B, Schiavon R, Sanhueza P, et al. Who presents past the gestational age limit for first trimester abortion in the public sector in Mexico City? PLoS One 2018;13:e0192547.

23 Miller S, Lehman T, Campbell M, et al. Misoprostol and declining abortion-related morbidity in Santo Domingo, Dominican Republic: a temporal association. BJOG 2005;112:1291-6.

24 Fiol V, Briozzo L, Labandera A, et al. Improving care of women at risk of unsafe abortion: implementing a risk-reduction model at the Uruguayan-Brazilian border. Int J Gynaecol Obstet 2012;118 Suppl 1:S21-7.

25 Moore AM, Ortiz J, Blades N, et al. Women's experiences using drugs to induce abortion acquired in the informal sector in Colombia: qualitative interviews with users in Bogotá and the coffee axis. Sex Reprod Health Matters 2021;29:1890868

26 Zamberlin N, Romero M, Ramos S. Latin American women's experiences with medical abortion in settings where abortion is legally restricted. Reprod Health 2012;9:34.

27 Ramos S, Romero M, Ramón Michel A. Health care providers opinions on abortion: a study for the implementation of the legal abortion public policy in the province of SANTA Fe, Argentina. Reprod Health 2014;11:72.

28 Erdman JN. Harm reduction, human rights, and access to information on safer abortion. Int J Gynaecol Obstet 2012;118:83-6.

29 Comisión Interamericana de Derechos Humanos. Acceso a la información en materia reproductiva desde Una perspectiva de derechos humanos, 2011.

30 Qureshi Z, Mehrtash H, Kouanda S, et al. Understanding abortionrelated complications in health facilities: results from who multicountry survey on abortion (MCS-A) across 11 sub-Saharan African countries. BMJ Glob Health 2021;6:e003702.

31 Calvert C, Owolabi OO, Yeung F, et al. The magnitude and severity of abortion-related morbidity in settings with limited access to abortion services: a systematic review and meta-regression. BMJ Glob Health 2018;3:e000692.

32 López Gómez A. Posibilidades Y resistencias a la incorporación del enfoque de derechos en Las prácticas de las/os profesionales de la salud. in: Investigación sobre aborto en América Latina Y El Caribe: Una agenda renovada para informar políticas públicas $E$ incidencia. CLACAI, 2015.

33 Zamberlin N. El estigma asociado al aborto como objeto de Estudio: Los primeros pasos en América Latina. in: Investigación sobre aborto en América Latina Y El Caribe: Una agenda renovada para informar políticas públicas E incidencia. CLACAl, 2015.

34 Leke RJI, de Gil MP, Távara L, et al. The FIGO Working group on the prevention of unsafe abortion: mandate and process for achievement. Int J Gynaecol Obstet 2010;110 Suppl:S20-4.

35 Olavarrieta CD, Garcia SG, Arangure A, et al. Women's experiences of and perspectives on abortion at public facilities in Mexico City three years following decriminalization. Int J Gynaecol Obstet 2012;118 Suppl 1:S15-20.

36 Romero M, Zamberlin N, Gianni MC. La calidad de la atención posaborto: un desafío para La salud pública Y Los derechos humanos. Salud Colect 2010;6:21-34.

37 Carneiro MF, Iriart JAB, Menezes GMS. "Left alone, but that's okay": paradoxes of the experience of women hospitalized due to induced abortion in Salvador, Bahia, Brazil. Interface 2013;45:405-18.

38 De Mucio B, Abalos E, Cuesta C, et al. Maternal near miss and predictive ability of potentially life-threatening conditions at selected maternity hospitals in Latin America. Reprod Health 2016;13:134.

39 Karolinski A, Mazzoni A, Belizán JM, et al. Lost opportunities for effective management of obstetric conditions to reduce maternal mortality and severe maternal morbidity in Argentina and Uruguay. Int J Gynaecol Obstet 2010;110:175-80.

40 Serruya SJ, Gómez Ponce de León R, Bahamondes MV, et al. EviSIP: using evidence to change practice through mentorship - an innovative experience for reproductive health in the Latin American and Caribbean regions. Glob Health Action 2020;13:1811482.

41 Veiga-Junior NN, Cavalari CA, Eugeni C, et al. Post-abortion contraception before hospital discharge after installation of a surveillance network in Brazil. Int J Gynaecol Obstet 2020;150:200-5.

42 Solar F, Rumante K, Valenzuela F, et al. Experiencia clínica del uso de la ficha SIP/CLAP en mujeres Con aborto espontáneo resuelto POR vía quirúrgica. Revista chilena de obstetricia y ginecología 2020;85:324-34.

43 Assifi AR, Berger B, Tunçalp Özge, et al. Women's awareness and knowledge of abortion laws: a systematic review. PLoS One 2016;11:e0152224.

44 Erdman JN, Johnson BR. Access to knowledge and the global abortion policies database. Int J Gynaecol Obstet 2018:142:120-4.

45 Erdman JN, Cook RJ. Decriminalization of abortion - A human rights imperative. Best Pract Res Clin Obstet Gynaecol 2020;62:11-24. 